\title{
Tear Film Pharmacokinetics and Systemic Absorption Following Topical Administration of $1 \%$ Prednisolone Acetate Ophthalmic Suspension in Dogs
}

\author{
Lionel Sebbag ${ }^{1,2 \star}$, Nicolette S. Kirner ${ }^{3}$, Larry W. Wulf ${ }^{4}$ and Jonathan P. Mochel ${ }^{2 \star}$ \\ ${ }^{1}$ Department of Veterinary Clinical Sciences, College of Veterinary Medicine, lowa State University, Ames, IA, United States, \\ ${ }^{2}$ Department of Biomedical Sciences, SMART Pharmacology, College of Veterinary Medicine, lowa State University, Ames, \\ IA, United States, ${ }^{3}$ Lloyd Veterinary Medical Center, College of Veterinary Medicine, lowa State University, Ames, IA, \\ United States, ${ }^{4}$ PhAST Laboratory, College of Veterinary Medicine, lowa State University, Ames, IA, United States
}

OPEN ACCESS

Edited by:

Chi-Chung Chou,

National Chung Hsing

University, Taiwan

Reviewed by:

Faqir Muhammad,

University of Agriculture,

Faisalabad, Pakistan

Benito Soto-Blanco,

Federal University of Minas

Gerais, Brazil

*Correspondence:

Lionel Sebbag

Isebbag@iastate.edu orcid.org/0000-0002-0103-0127

Jonathan P. Mochel

jmoche/@iastate.edu

orcid.org/0000-0002-0997-3111

Specialty section:

This article was submitted to Veterinary Pharmacology and Toxicology,

a section of the journa

Frontiers in Veterinary Science

Received: 10 June 2020 Accepted: 08 October 2020

Published: 27 October 2020

Citation:

Sebbag L, Kirner NS, Wulf LW and

Mochel JP (2020) Tear Film

Pharmacokinetics and Systemic

Absorption Following Topical

Administration of 1\% Prednisolone

Acetate Ophthalmic Suspension in

Dogs. Front. Vet. Sci. 7:571350.

doi: 10.3389/fvets.2020.571350
The study aimed to determine the tear film pharmacokinetics following topical administration of $1 \%$ prednisolone acetate-assessing whether two drops would provide a superior kinetic profile compared to one drop-and to determine the fraction of an eye drop that reaches the systemic circulation in dogs. Two separate experiments were conducted in eight healthy Beagle dogs: (i) Instillation of 1 drop (35 $\mu \mathrm{L})$ or 2 drops $(70 \mu \mathrm{L})$ of $1 \%$ prednisolone acetate ophthalmic suspension in each eye, followed by tear collections with Schirmer strips from 0 to 720 min; (ii) Instillation of 1 or 2 drops of $1 \%$ prednisolone acetate in both eyes 4 times daily for 3 days, followed by blood collection 10-15 min after each topical administration on Day 3. Tear and blood samples were analyzed with high performance liquid chromatography to determine the levels of prodrug (prednisolone acetate), active metabolite (prednisolone) and total prednisolone (prednisolone $_{\text {total }}=$ prodrug + active metabolite). Prednisolone levels represented 10

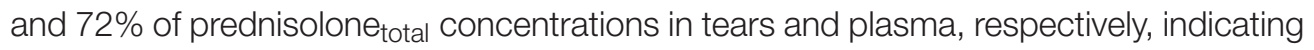
a greater hydrolysis of prodrug in the blood vs. tear compartment. For eyes receiving

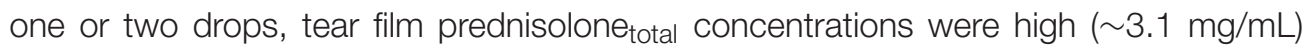
immediately following topical administration but rapidly decreased by $\sim 45 \%$ at 1 min and $\sim 95 \%$ at $15 \mathrm{~min}$. No differences were noted between 1 vs. 2 drops in tear film prednisolone $e_{\text {total }}$ concentrations (including maximal concentration, $\mathrm{C}_{\max }$ ) or residual drug levels in tears at any time point $(P \geq 0.097)$; however, instillation of 2 drops provided a higher average tear concentration $\left(\mathrm{C}_{\text {avg }}\right)$ and overall drug exposure to the ocular surface $\left(A \cup C_{\text {last}}\right)$ over the 12-h sampling period $(P=0.009)$. Average plasma

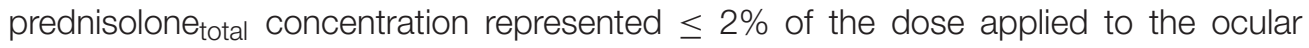
surface, and did not differ significantly for dogs receiving 1 drop $(17 \mathrm{ng} / \mathrm{mL})$ or 2 drops ( $20 \mathrm{ng} / \mathrm{mL}) 4$ times daily for 3 days $(P=0.438$ ). In sum, topical corticotherapy is beneficial for inflammatory conditions of the canine anterior segment given the relatively high concentrations achieved in tears, although caution is warranted to prevent unwanted local or systemic adverse effects.

Keywords: prednisolone acetate, pharmacokinetics, corticosteroid, tear film, systemic absorption, ocular pharmacology, tear collection, canine 


\section{INTRODUCTION}

Topically administered corticosteroid is a common practice in human and veterinary ophthalmology $(1,2)$. Owing to a wide range of biologic effects, from anti-inflammatory to immunosuppression, topical corticosteroids are indicated for various conditions affecting the ocular surface and the anterior segment of the eye, including dacryocystitis, episcleritis, conjunctivitis, keratitis, and anterior uveitis $(1,2)$. Multiple formulations of ocular corticosteroids are commercially available, and the choice is often dictated by the properties of the specific drug and associated formulation; in practice, $1 \%$ prednisolone acetate is often considered superior to other formulations (e.g., betamethasone phosphate, dexamethasone alcohol, or disodium phosphate) as the acetate derivative of the steroid provides superior penetration in the cornea and anterior chamber $(1,3,4)$. However, despite well-documented benefits of topical prednisolone acetate for various ocular disorders, the basic pharmacokinetics (PK) of the drug has yet to be elucidated. This knowledge would help clinicians optimize frequency of administration and better understand the potential toxicity associated with topical corticotherapy at a local and systemic level $(1,2)$.

Upon instillation on the ocular surface, prednisolone can exert local and systemic effects as follows: (i) mixing with tear film and retention on the ocular surface (tears, conjunctival cul-de-sac); (ii) penetration into the cornea and aqueous humor; and (iii) systemic absorption into conjunctival vessels and nasolacrimal drainage, where the drug can be absorbed by the nasal mucosa or be swallowed (5). As the first step in ocular pharmacology, tear film PK provides important information about the instilled drug (e.g., concentration, precorneal retention time), as well as an indirect and non-invasive method to estimate intraocular drug concentrations, especially for drugs such as prednisolone acetate that readily permeate through the corneal barrier (6). In dogs-a species better suited for translational research in pharmacology than common laboratory animals (7-9) - tear film PK has been described for three ophthalmic drugs to date: fusidic acid (10), ciprofloxacin (11), and oxytetracycline (12). However, direct extrapolation with prednisolone acetate is likely inaccurate as the PK of topically administered medications greatly depends on the physicochemical properties of the formulation (e.g., $\mathrm{pH}$, viscosity, particle size) (13). In particular, prednisolone acetate is a prodrug that requires ester hydrolysis to obtain the active metabolite prednisolone (14); further, prednisolone acetate is a suspension and not a solution, a formulation that could theoretically increase the retention time on the ocular surface as drug particles are sequestered in the conjunctival cul-de-sac $(15,16)$.

The main purpose of the study was to determine the tear film pharmacokinetics following topical administration of $1 \%$ prednisolone acetate in canine eyes, and to assess whether topical administration of 2 drops would provide a superior PK profile compared to a single drop. Prednisolone acetate is a suspension formulation that enhances drug penetration through the cornea, converted into the active metabolite (prednisolone) by esterases following topical administration to the eye (14). Since most of the esterase activity occurs in ocular tissues (e.g., cornea, anterior uvea) and not in tears (17), prednisolone total (prednisolone acetate + prednisolone) was selected as the study's main outcome to provide information about the total amount of drug available for drug diffusion into the eye. Another study objective was to evaluate the plasma drug concentrations when topical $1 \%$ prednisolone acetate drops are instilled at a dosage frequency similar to canine patients (i.e., four times daily).

\section{MATERIALS AND METHODS}

\section{Animals}

Eight Beagle dogs were enrolled in the study. All dogs were neutered (four male, four female), aged 3.0-3.5 years, weighed $7.5-10 \mathrm{~kg}$, and confirmed to be healthy based on a complete physical and ophthalmic examination, including Schirmer tear test-1 (Eye Care Product Manufacturing LLC, Tucson, AZ, United States), tonometry (TonoVet, Icare Finland Oy, Espoo, Finland), slit-lamp biomicroscopy (SL-17; Kowa Company, Ltd., Tokyo, Japan) and indirect ophthalmoscopy (Keeler Vantage; Keeler Instruments, Inc., Broomall, PA, United States). The study was approved by the Institutional Animal Care and Use Committee of Iowa State University (IACUC-18-398), and adhered to the Association for Research in Vision and Ophthalmology (ARVO) statement for Use of Animals in Ophthalmic and Vision Research.

\section{Tear Film Pharmacokinetics Following Instillation of 1 vs. 2 Drops}

In each dog, one eye was chosen at random (Excel software) to receive $35 \mu \mathrm{L}$ (one drop) of $1 \%$ prednisolone acetate ophthalmic suspension (Sandoz Inc., Princeton, NJ, United States), while the other eye received $70 \mu \mathrm{L}$ (two drops), and this selection was kept constant throughout the study. The experiment extended over 13 consecutive days, with topical prednisolone acetate delivered with a pipette at 8:00 a.m. (each day) and tear fluid collected with dye-free Schirmer strips at the following time points (one collection per day): $0 \mathrm{~min}$ (i.e., immediately after instillation and blinking), 1, 3, 5, 15, 30, 45, 60, 90, 120, 240, 480, and $720 \mathrm{~min}$. At completion of tear collection each day, both eyes were thoroughly rinsed with eyewash (Eye Wash, OcuSOFT Inc., Richmond, TX, United States) to avoid any carryover of prednisolone acetate from 1 day to another. For eye drop administration, $1 \%$ prednisolone acetate ophthalmic suspension was transferred to Eppendorf vials that were vigorously shaken for $1 \mathrm{~min}$ with a vortex mixer (LP vortex mixer, Thermo scientific Inc., Waltham, MA, United States) to homogenize the distribution of drug particles, followed by accurate administration of the selected volume $\left(35\right.$ or $70 \mu \mathrm{L}$ ) with a pipette (Eppendorf ${ }^{\circledR}$ Reference $2,10-100 \mu \mathrm{L}$ ). For tear collection, the bent tip of a dye-free Schirmer tear strip (Eye Care Product Manufacturing) was placed in the ventrolateral conjunctival fornix of each eye, removed when the 20-mm mark of wetness was reached and transferred to a 2-mL Eppendorf tube (18). In a separate room (to avoid contamination), the dry distal portion of each Schirmer strip was spiked with $5 \mu \mathrm{L}$ of the internal standard prednisone-d7 
(Toronto Research Chemicals, North York, Canada), prepared as $10 \mathrm{ng} / \mu \mathrm{L}$ solution in acetonitrile:water (50:50 v/v). Eppendorf tubes were stored at $-80^{\circ} \mathrm{C}$ until analysis. A combination of centrifugation and solvent elution was used to extract tears from Schirmer strips, using a simplified and optimized method compared to previously reported technique $(9,18,19)$ : once thawed, each Schirmer strip was placed into a $0.2-\mathrm{mL}$ tube that was pre-punctured at its bottom with an 18-gauge needle, secured into a 2-mL Eppendorf tube via adhesive tape and centrifuged for $2 \mathrm{~min}$ at 3,884 g. After the first centrifugation, the strip in the $0.2-\mathrm{mL}$ tube was wetted with $75 \mu \mathrm{L}$ of methyl tert-butyl ether (MTBE) and allowed to sit for $5 \mathrm{~min}$; of note, this particular solvent was chosen based on its superior ability to extract prednisolone from Schirmer strips as compared to methanol, acetonitrile, and methanol:water 50:50 v/v (pilot experiment using 10 STT per solvent; data not shown). The combination of tubes was centrifuged again at $3,884 \mathrm{~g}$ for $2 \mathrm{~min}$. Next, 150 $\mu \mathrm{L}$ acetonitrile was added to each $2-\mathrm{mL}$ tube, vortexed for $30 \mathrm{~s}$, centrifuged at 3,824 g for $1 \mathrm{~min}$, nitrogen dried at 5-15 psi for $10 \mathrm{~min}$, reconstituted with $150 \mu \mathrm{L}$ acetonitrile:water $(25: 75 \mathrm{v} / \mathrm{v})$, vortexed for $30 \mathrm{~s}$, centrifuged at 3,884 $\mathrm{g}$ for $1 \mathrm{~min}$ then transferred to LC-MS vials fitted with glass inserts.

\section{Systemic Absorption Following Instillation of 1 vs. 2 Drops}

Each dog was chosen at random (Excel software) to receive 35 $\mu \mathrm{L}$ or $70 \mu \mathrm{L}$ of ophthalmic $1 \%$ prednisolone acetate suspension in both eyes, four times a day (8 a.m., 12 p.m., 4 p.m., 8 p.m.) for three consecutive days. The course was repeated with each dog receiving the opposite dose following a $48 \mathrm{~h}$ washout period, a duration selected on the basis of serum concentrations below limit of quantification at $24 \mathrm{~h}$ after topical corticosteroid use in horses (20). On Day 3 of each experiment, blood was collected via peripheral venipuncture $10-15 \mathrm{~min}$ following each topical administration, for a total of 4 blood collections per dog and per dose regimen. Blood samples were transferred to EDTA tubes, centrifuged for $30 \mathrm{~min}$ at $1,300 \mathrm{~g}\left(4^{\circ} \mathrm{C}\right)$, and the supernatant plasma was transferred to 2-mL Eppendorf tubes that were stored at $-80^{\circ} \mathrm{C}$ until analysis.

\section{Drug Quantification in Tears and Plasma Samples}

Before study initiation, blank canine tears $(\sim 15 \mathrm{~mL})$ were collected from the same Beagle dogs using ophthalmic sponges as previously described (21), and blank plasma samples were collected by venipuncture and centrifugation in EDTA tubes. For plasma, 10 standard curve solutions were prepared by spiking blank canine plasma with stock solution of prednisolone and prednisolone acetate (Sigma Chemical, St. Louis, MO, United States) to obtain the following concentrations: $0.5,1,2$, 5, 10, 20, 50, 100, 200, and $500 \mathrm{ng} / \mathrm{mL}$. For tears, 9 standard curve solutions were prepared by spiking blank canine tears with stock solution of prednisolone acetate to obtain the following concentrations: $0.02,0.075,0.2,0.5,1.5,5,20,50$ and $100 \mu \mathrm{g} / \mathrm{mL}$. Tear calibration curve samples were processed in a similar manner to biological tear samples, which involved wetting
Schirmer strips with standard solution until the 20 -mm mark was reached, spiking prednisone-d7 internal standard onto the distal (dry) portion of the strips, and extracting tears with a combination of centrifugation and elution in MTBE (9). Of note, tear samples collected at $0-30 \mathrm{~min}$ following topical instillation of $1 \%$ prednisolone acetate were diluted with blank tears spiked with prednisone- $\mathrm{d} 7$ to ensure the measured concentration would fall within the range of the generated standard curve; specifically, the dilution factors were 1:40 for samples collected at $0 \mathrm{~min}$ and $1 \mathrm{~min}, 1: 30$ for $3 \mathrm{~min}$ and $5 \mathrm{~min}$, and 1:5 for $15 \mathrm{~min}$ and $30 \mathrm{~min}$. Three quality control (QC) samples were analyzed at each run $(0.05,0.75$ and $10 \mu \mathrm{g} / \mathrm{mL}$ for tears, 3,15 and $75 \mathrm{ng} / \mathrm{mL}$ for plasma). Concentrations of prednisolone and prednisolone acetate in canine tears and plasma were determined using high-pressure liquid chromatography (Surveyor Pump and Autosampler, Thermos Scientific, San Jose, CA, United States), with separation achieved with an ACE Ultracore C18 column $(100 \mathrm{~mm} \times 2.1 \mathrm{~m}, 2.5 \mu \mathrm{m}$; Mac Mod Analytical, Chadds Cord, $\mathrm{PA}$, United States) maintained at $50^{\circ} \mathrm{C}$, and detection by triple quadrupole mass spectrometry (TSQ Quantum Discovery Max). Injection volume was set to $12.5 \mu \mathrm{L}$. The mobile phases consisted of $0.1 \%$ formic acid in water (A) and $0.1 \%$ formic acid in acetonitrile (B) at a flow rate of $0.25 \mathrm{~mL} / \mathrm{min}$. The mobile phase began at $25 \% \mathrm{~B}$ with a linear gradient to $95 \% \mathrm{~B}$ in $6 \mathrm{~min}$, which was maintained for $1 \mathrm{~min}$ at $0.35 \mathrm{~mL} / \mathrm{min}$, followed by re-equilibration to $25 \% \mathrm{~B}$ at $0.35 \mathrm{~mL} / \mathrm{min}$ for $2 \mathrm{~min}$. The chromatic peaks for the internal standard, prednisolone (each eluted at $2.77 \pm 0.05 \mathrm{~min}$ ) and prednisolone acetate (eluted at $4.38 \pm 0.05 \mathrm{~min}$ ) were integrated using Xcalibur software (Thermo Scientific, San Jose, CA) (Figure 1). Drug quantitation was based on linear regression analysis of calibration curves (weighted $1 / \mathrm{X}$ ) using the analyte to internal standard area ratio, resulting in three measures for each sample: prednisolone acetate (prodrug), prednisolone (active metabolite) and prednisolone total (prodrug + active metabolite). Of note, the calibration curve of prednisolone acetate was used for calculation of prednisolone concentrations in tears (as only prednisolone acetate was spiked into the blank tears for standard curve solutions). Therefore, prednisolone concentrations were adjusted by $+19 \%$ to account for the additional response of prednisolone above that of prednisolone acetate, a correction factor that was calculated as the average response differential between both steroids in mixed solutions varying in concentrations from 50 to $1,000 \mathrm{ng} / \mathrm{mL}$. Drug recovery from Schirmer strips was evaluated by wetting 10 Schirmer strips until 20 -mm mark with $100 \mu \mathrm{g} / \mathrm{mL}$ prednisolone acetate, followed by the same extraction and analysis methods used for biological and calibration samples. Calibration curves exhibited a correlation coefficient $\left(r^{2}\right)$ exceeding 0.99 across the concentration range. In tears, the limit of quantitation (LOQ) for both prednisolone and prednisolone acetate was $0.075 \mu \mathrm{g} / \mathrm{mL}$ with a limit of detection (LOD) for both analytes of $0.005 \mu \mathrm{g} / \mathrm{mL}$. In plasma, the LOQ for both prednisolone and prednisolone acetate was $1.0 \mathrm{ng} / \mathrm{mL}$ with an LOD of $0.2 \mathrm{ng} / \mathrm{mL}$.

\section{Data Analysis}

Normality of the data was assessed using the Shapiro-Wilk test. A mixed model for repeated measures (MMRM) was fitted to 


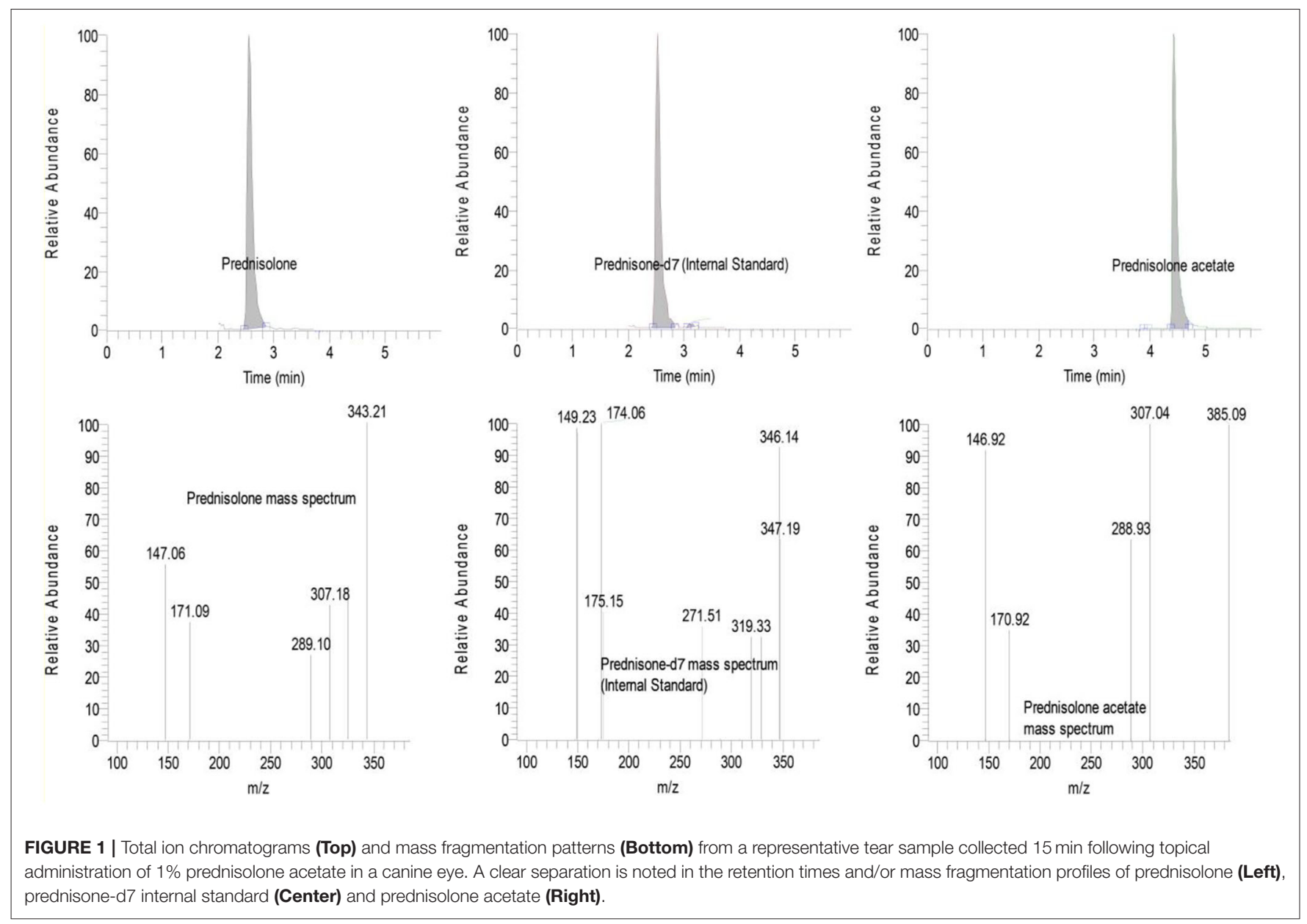

the data using the $\mathrm{R}$ software version 3.6.0 (8). In the model, tear film prednisolone $e_{\text {total }}$ or prednisolone concentration was the response variable, the group ( 1 or 2 drops), time ( 0 to $720 \mathrm{~min}$ ) and group-by-time interaction were treated as fixed effects, and the animal and animal-by-group interaction were treated as random effects, using animal as block. After the model was fit, the fixed effects were tested, and comparisons between 1 vs. 2 drops were made for the following outcomes: (i) prednisolone total $_{\text {or }}$ prednisolone concentrations in tears at each time point, and (ii)

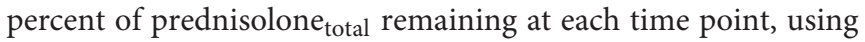
the baseline data of 1 drop for both groups in order to account for the different volumes instilled in both eyes. Further, a noncompartmental PK analysis was conducted with PKanalix version 2019R1 (Lixoft, Orsay, France) and the linear-log trapezoidal rule for calculation of the area under the concentration-time curve $\left(\mathrm{AUC}_{\text {last }}\right)$; however, since the drug decay over time was non-linear in tears-a finding due to non-constant timing of blinking (mechanism contributing to prednisolone clearance in tears), among others-the analysis cannot determine all PK parameters accurately (e.g., terminal half-life, clearance) and is thereby focused on the following parameters: $\mathrm{AUC}_{\text {last }}$, average tear film concentration $\left(\mathrm{C}_{\mathrm{avg}}\right)$ and maximal tear film concentration $\left(\mathrm{C}_{\max }\right)$. Paired $t$-tests were used to compare $\mathrm{AUC}_{\text {last }}, \mathrm{C}_{\mathrm{avg}}$ and $\mathrm{C}_{\max }$ of prednisolone total $_{\text {and prednisolone }}$ between eyes receiving 1 vs. 2 drops of $1 \%$ prednisolone acetate, as well as plasma prednisolone total $_{\text {concentration in }}$ dogs receiving 1 drop or 2 drops of $1 \%$ prednisolone acetate in both eyes for 3 days, assessing each session separately (8 a.m., 12 p.m., 4 p.m., 8 p.m.) and all 4 sessions combined. Last, the relative absorption of prednisolone total $_{\text {in the systemic }}$ circulation was calculated as the ratio of the drug amount administered (700 $\mu \mathrm{g}$ and $1,400 \mu \mathrm{g}$ for 1 and 2 drops of $1 \%$ prednisolone acetate given to both eyes, respectively) by the drug amount present in the blood-determined as the average plasma concentration at steady state multiplied by $815 \mathrm{~mL}$ (total blood volume in a 10-kg Beagle dog) (22). Statistical analyses were performed with SigmaPlot 14.0 (Systat software, Point Richmond, CA, United States), and $P<0.05$ were considered significant.

\section{RESULTS}

Results are presented as mean \pm standard deviation (range) as data was normally distributed $(P>0.05)$. Recovery of prednisolone acetate from Schirmer strips was $90.3 \pm 7.9 \%$ (79.9-106.8\%).

\section{Tear Film Concentrations}

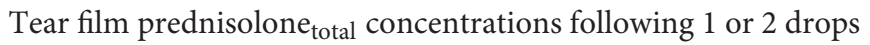
of $1 \%$ prednisolone acetate ranged from $1-3786$ to $1-3671 \mu \mathrm{g} / \mathrm{mL}$, 
respectively (Figure 2), with no statistical differences $(P \geq$ 0.097 ) between both groups at any time point. Maximal tear film concentration $\left(\mathrm{C}_{\max }\right)$ occurred at $\mathrm{t}=0 \mathrm{~min}$ for eyes receiving 1 drop $(3,080 \pm 475 \mu \mathrm{g} / \mathrm{mL}$; range $2,476-3,786 \mu \mathrm{g} / \mathrm{mL})$ or 2 drops $(3,160 \pm 404 \mu \mathrm{g} / \mathrm{mL}$; range $2,314-3,671 \mu \mathrm{g} / \mathrm{mL}$; $P=0.675)$ of $1 \%$ prednisolone acetate. Then, tear film prednisolone concentrations dropped rapidly by $\sim 45 \%$ at $1 \mathrm{~min}$ and $\sim 95 \%$ at $15 \mathrm{~min}$, with no statistical differences $(P \geq 0.153)$ in residual drug levels at any time point between both doses (Table 1). However, the average tear film concentration $\left(\mathrm{C}_{\mathrm{avg}}\right)$ and the area under the concentration-time curve $\left(\mathrm{AUC}_{\text {last }}\right)$ were significantly greater $(P=0.009)$ for eyes receiving 2 drops $(53 \pm 17 \mu \mathrm{g} / \mathrm{mL}$, range $34-87 \mu \mathrm{g} / \mathrm{mL}$; and $38,331 \pm 12,026$ min* $\mu \mathrm{g} / \mathrm{mL}$; range $24,135-62,358 \mathrm{~min}^{*} \mu \mathrm{g} / \mathrm{mL}$ ) compared to 1 drop $(38 \pm 14 \mu \mathrm{g} / \mathrm{mL}$, range $14-56 \mu \mathrm{g} / \mathrm{mL}$; and $27,604 \pm 10,002$ $\mathrm{min}^{*} \mu \mathrm{g} / \mathrm{mL}$; range 10,434-40,399 $\mathrm{min}^{*} \mu \mathrm{g} / \mathrm{mL}$ ).

Tear film prednisolone concentrations following 1 or 2 drops of $1 \%$ prednisolone acetate ranged from $0.3-115.7 \mu \mathrm{g} / \mathrm{mL}$ and $0.3-68.6 \mu \mathrm{g} / \mathrm{mL}$ respectively (Table 2 ), with no statistical differences $(P \geq 0.083)$ between both groups at any time point. On average, the active metabolite prednisolone represented $10 \%$ of total drug level over the collection period (0-720 min). Table 3 summarizes the PK parameters for prednisolone total $_{\text {and }}$ prednisolone for both doses.

\section{Plasma Concentrations}

At steady state, no significant differences $(P \geq 0.113)$ were noted in plasma prednisolone $e_{\text {total }}$ concentrations following each

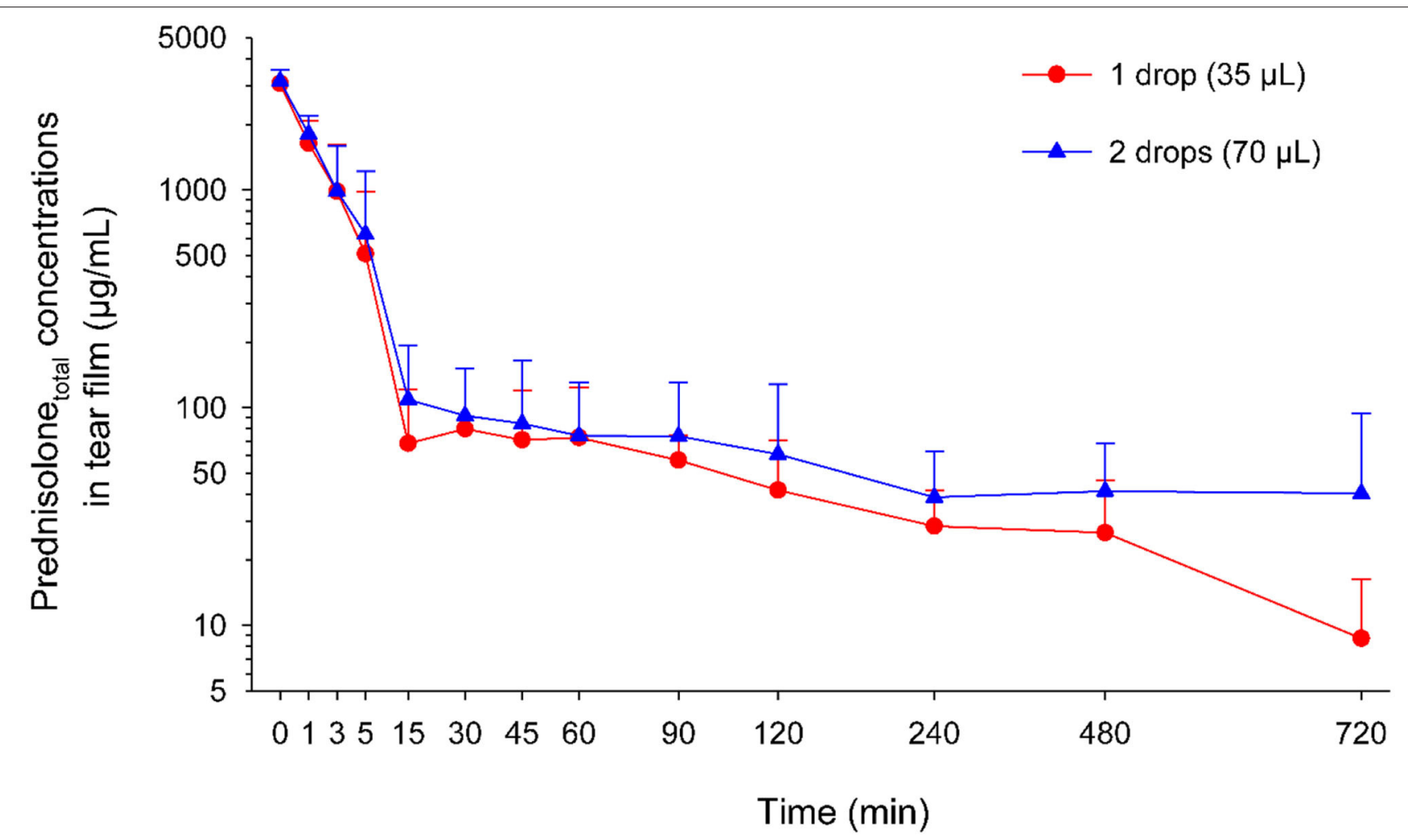

FIGURE 2 | Scatter plot depicting the mean + SD of tear film prednisolonetotal concentrations over time in canine eyes receiving either one drop (35 $\mu$ L; red circles) or two drops ( $70 \mu \mathrm{L}$; blue triangles) of $1 \%$ prednisolone acetate ophthalmic suspension.

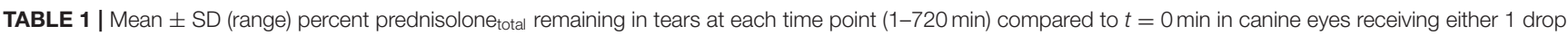
(35 $\mu \mathrm{L})$ or 2 drops $(70 \mu \mathrm{L})$ of $1 \%$ prednisolone acetate.

\begin{tabular}{|c|c|c|c|c|c|c|c|c|c|c|c|c|}
\hline $\begin{array}{l}\text { Time } \\
\text { (min) }\end{array}$ & 1 & 3 & 5 & 15 & 30 & 45 & 60 & 90 & 120 & 240 & 480 & 720 \\
\hline $\begin{array}{l}1 \text { drop } \\
\text { (35 } \mu L)\end{array}$ & $\begin{array}{c}53.5 \pm 15.0 \\
(28.4-76.1)\end{array}$ & $\begin{array}{c}31.6 \pm 18.9 \\
(2.5-54.1)\end{array}$ & $\begin{array}{c}16.9 \pm 16.0 \\
(2.3-49.4)\end{array}$ & $\begin{array}{l}2.2 \pm 1.6 \\
(0.6-5.5)\end{array}$ & $\begin{array}{l}2.5 \pm 2.2 \\
(0.3-6.8)\end{array}$ & $\begin{array}{l}2.2 \pm 1.2 \\
(0.9-4.5)\end{array}$ & $\begin{array}{l}2.5 \pm 2.0 \\
(0.4-6.5)\end{array}$ & $\begin{array}{l}1.9 \pm 0.5 \\
(1.0-2.3)\end{array}$ & $\begin{array}{l}1.3 \pm 0.7 \\
(0.5-2.8)\end{array}$ & $\begin{array}{l}0.9 \pm 0.5 \\
(0.4-1.8)\end{array}$ & $\begin{array}{c}0.9 \pm 0.6 \\
(0.2-1.9)\end{array}$ & $\begin{array}{c}0.3 \pm 0.2 \\
(0-0.6)\end{array}$ \\
\hline $\begin{array}{l}2 \text { drops } \\
(70 \mu L)\end{array}$ & $\begin{array}{l}57.3 \pm 10.6 \\
(39.8-74.0)\end{array}$ & $\begin{array}{c}31.7 \pm 18.7 \\
(4.5-63.4)\end{array}$ & $\begin{array}{c}19.8 \pm 17.3 \\
(1.4-46.4)\end{array}$ & $\begin{array}{l}3.5 \pm 2.7 \\
(0.7-8.2)\end{array}$ & $\begin{array}{l}3.0 \pm 2.0 \\
(0.7-6.5)\end{array}$ & $\begin{array}{l}2.7 \pm 2.5 \\
(0.8-8.6)\end{array}$ & $\begin{array}{l}2.4 \pm 1.9 \\
(0.3-5.8)\end{array}$ & $\begin{array}{l}2.3 \pm 1.8 \\
(1.2-6.7)\end{array}$ & $\begin{array}{l}1.9 \pm 2.1 \\
(0.5-6.5)\end{array}$ & $\begin{array}{l}1.2 \pm 0.8 \\
(0.4-2.6)\end{array}$ & $\begin{array}{l}1.4 \pm 1.2 \\
(0.6-4.2)\end{array}$ & $\begin{array}{c}1.3 \pm 1.8 \\
(0-5.4)\end{array}$ \\
\hline$P$-value & 0.153 & 0.483 & 0.220 & 0.358 & 0.450 & 0.449 & 0.512 & 0.449 & 0.430 & 0.470 & 0.440 & 0.393 \\
\hline
\end{tabular}

Results are reported in \%. 
TABLE 2 | Mean \pm SD (range) tear film prednisolone concentrations at 0-720 min in canine eyes receiving either 1 drop (35 $\mu L$ ) or 2 drops (70 $\mu L$ ) of $1 \%$ prednisolone acetate.

\begin{tabular}{|c|c|c|c|c|c|c|c|c|c|c|c|c|c|}
\hline $\begin{array}{l}\text { Time } \\
\text { (min) }\end{array}$ & 0 & 1 & 3 & 5 & 15 & 30 & 45 & 60 & 90 & 120 & 240 & 480 & 720 \\
\hline $\begin{array}{l}1 \text { drop } \\
\text { (35 } \mu \text { L) }\end{array}$ & $\begin{array}{l}62.0 \pm 25.5 \\
(32.2-115.7)\end{array}$ & $\begin{array}{c}44.6 \pm 16.8 \\
(9.6-62.1)\end{array}$ & $\begin{array}{l}44.3 \pm 13.1 \\
(22.9-63.7)\end{array}$ & $\begin{array}{l}27.1 \pm 9.5 \\
(11.4-41.1)\end{array}$ & $\begin{array}{l}8.4 \pm 6.7 \\
(1.8-20.1)\end{array}$ & $\begin{array}{l}8.3 \pm 6.0 \\
(2.1-18.2)\end{array}$ & $\begin{array}{l}8.1 \pm 3.4 \\
(4.5-13.1)\end{array}$ & $\begin{array}{l}5.2 \pm 2.1 \\
(2.3-8.4)\end{array}$ & $\begin{array}{l}6.2 \pm 4.2 \\
(2.1-15.6)\end{array}$ & $\begin{array}{l}6.0 \pm 2.1 \\
(2.6-8.1)\end{array}$ & $\begin{array}{c}3.9 \pm 2.0 \\
(1.4-7.3)\end{array}$ & $\begin{array}{c}3.3 \pm 2.3 \\
(0.5-6.5)\end{array}$ & $\begin{array}{l}1.4 \pm 1.1 \\
(0.3-2.8)\end{array}$ \\
\hline $\begin{array}{l}2 \text { drops } \\
(70 \mu L)\end{array}$ & $\begin{array}{c}46.4 \pm 10.0 \\
(37.2-68.6)\end{array}$ & $\begin{array}{c}38.2 \pm 13.5 \\
(17.6-56.9)\end{array}$ & $\begin{array}{c}36.9 \pm 13.4 \\
(15.8-58.6)\end{array}$ & $\begin{array}{c}30.6 \pm 20.5 \\
(8.6-58.5)\end{array}$ & $\begin{array}{l}11.4 \pm 8.2 \\
(2.5-24.0)\end{array}$ & $\begin{array}{l}9.8 \pm 4.9 \\
(4.1-18.4)\end{array}$ & $\begin{array}{c}7.7 \pm 6.2 \\
(0.8-20.2)\end{array}$ & $\begin{array}{l}8.8 \pm 9.9 \\
(3.1-32.2)\end{array}$ & $\begin{array}{l}6.1 \pm 2.1 \\
(3.4-8.4)\end{array}$ & $\begin{array}{l}5.6 \pm 3.2 \\
(3.0-11.9)\end{array}$ & $\begin{array}{l}4.8 \pm 3.6 \\
(1.5-10.8)\end{array}$ & $\begin{array}{l}4.1 \pm 3.9 \\
(0.3-12.1)\end{array}$ & $\begin{array}{l}4.0 \pm 2.1 \\
(1.7-7.5)\end{array}$ \\
\hline$P$-value & 0.083 & 0.487 & 0.183 & 0.378 & 0.463 & 0.459 & 0.495 & 0.449 & 0.441 & 0.469 & 0.459 & 0.404 & 0.195 \\
\hline
\end{tabular}

Results are reported in $\mu \mathrm{g} / \mathrm{mL}$.

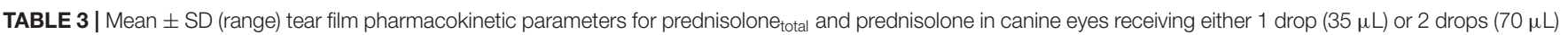
of $1 \%$ prednisolone acetate ophthalmic suspension: maximal concentration $\left(\mathrm{C}_{\mathrm{max}}\right)$, average concentration $\left(\mathrm{C}_{\text {avg }}\right)$ and area under the concentration-time curve $\left(\mathrm{AUC} \mathrm{C}_{\text {last }}\right)$.

\begin{tabular}{|c|c|c|c|c|c|c|}
\hline & \multicolumn{3}{|c|}{ Prednisolone $_{\text {total }}$} & \multicolumn{3}{|c|}{ Prednisolone } \\
\hline & $\begin{array}{c}C_{\max } \\
(\mu \mathrm{g} / \mathrm{mL})\end{array}$ & $\begin{array}{c}C_{\text {avg }} \\
(\mu \mathrm{g} / \mathrm{mL})\end{array}$ & $\begin{array}{c}\text { AUC }_{\text {last }} \\
\left(\mathrm{min}^{\star} \mu \mathrm{g} / \mathrm{mL}\right)\end{array}$ & $\begin{array}{c}C_{\max } \\
(\mu \mathrm{g} / \mathrm{mL})\end{array}$ & $\begin{array}{c}\text { C }_{\text {avg }} \\
(\mu \mathrm{g} / \mathrm{mL})\end{array}$ & $\begin{array}{c}\text { AUC }_{\text {last }} \\
\left(\mathrm{min}^{\star} \mu \mathrm{g} / \mathrm{mL}\right)\end{array}$ \\
\hline 1 drop (35 $\mu L)$ & $\begin{array}{c}3,080 \pm 475 \\
(2,476-3,786)\end{array}$ & $\begin{array}{c}38 \pm 14 \\
(14-56)\end{array}$ & $\begin{array}{c}27,604 \pm 10,002 \\
(10,434-40,399)\end{array}$ & $\begin{array}{l}66 \pm 24 \\
(32-116)\end{array}$ & $\begin{array}{l}14 \pm 3 \\
(6-17)\end{array}$ & $\begin{array}{r}2,998 \pm 1,112 \\
(1,026-4,342)\end{array}$ \\
\hline 2 drops $(70 \mu L)$ & $\begin{array}{c}3,160 \pm 404 \\
(2,314-3,671)\end{array}$ & $\begin{array}{l}53 \pm 17 \\
(34-87)\end{array}$ & $\begin{array}{c}38,331 \pm 12,026 \\
(24,135-62,358)\end{array}$ & $\begin{array}{l}50 \pm 10 \\
(40-69)\end{array}$ & $\begin{array}{l}13 \pm 4 \\
(7-19)\end{array}$ & $\begin{array}{l}3,783 \pm 1,221 \\
(2,193-5,742)\end{array}$ \\
\hline$P$-value & 0.675 & 0.009 & 0.009 & 0.135 & 0.452 & 0.112 \\
\hline
\end{tabular}

of the 4 topical administrations (8a.m., 12 p.m., 4 p.m., 8 p.m.) whether dogs received 1 drop or 2 drops of $1 \%$ prednisolone acetate in each eye. Similarly, mean \pm SD plasma prednisolone $_{\text {total }}$ concentration for 1 drop $(17.0 \pm 11.0 \mathrm{ng} / \mathrm{mL}$, range $6.0-50.3 \mathrm{ng} / \mathrm{mL})$ and 2 drops $(20.0 \pm 17.1 \mathrm{ng} / \mathrm{mL}$, range $5.4-93.9 \mathrm{ng} / \mathrm{mL})$ did not differ significantly $(P=0.438)$ when all 4 sessions at Day 3 where combined. Prednisolone concentrations varied from 3.9 to $34.0 \mathrm{ng} / \mathrm{mL}$ and represented $72 \%$ of total prednisolone concentration in plasma. The relative absorption of topical drug in the blood compartment was 2.0 and $1.2 \%$ for dogs receiving 1 or 2 drops of prednisolone acetate in both eyes, respectively.

\section{DISCUSSION}

The present study describes the tear film pharmacokinetics of topical $1 \%$ prednisolone acetate (one or two drops) and estimates the fraction of the drug that is absorbed into the systemic circulation of dogs. Of note, the study did not solely report the active metabolite (prednisolone) but instead focused on the overall drug concentration (prednisolone total ) as it better represents the amount of drug that is available for diffusion into the eye or absorption into the systemic circulation; in fact, the majority of esterase activity that converts prednisolone acetate to prednisolone is located in ocular tissues (e.g., cornea, anterior uvea) and not the tear compartment (17). At first glance, tear film kinetics appeared comparable for eyes receiving 1 or 2 drops of the ophthalmic suspension as there were no statistical differences in the drug concentrations or residual drug levels at each timepoint, and the precorneal retention time was relatively short in both groups ( $>95 \%$ drug loss at $15 \mathrm{~min}$ ). However, further assessment showed that the average tear film concentration $\left(\mathrm{C}_{\mathrm{avg}}\right)$ and the overall drug exposure (AUClast) were both significantly higher (by $39 \%$ ) in eyes receiving two vs. one drop of $1 \%$ prednisolone acetate. This finding contrasts with topical instillation of $1 \%$ fluorescein solution in dogs (8), and could be partly explained by a larger amount of drug particles being sequestered in the conjunctival cul-de-sac $(15,16)$ when two drops of an ophthalmic suspension are applied to the ocular surface. Further studies are needed to verify this hypothesis and determine whether this "statistically significant" finding is at all significant from a clinical perspective (i.e., therapeutic benefit, toxicity). The authors suspect differences between 1 vs. 2 drops are likely not relevant in practice as (i) tear film prednisolone levels were $>0.4 \mathrm{ng} / \mathrm{mL}\left(10^{-9} \mathrm{M}\right)$ in all dogs throughout the $12-\mathrm{h}$ sampling time, a concentration shown to decrease the expression of deleterious cytokines and matrix metalloproteinases in a rat model of keratitis (23); and (ii) tear film prednisolone levels only exceeded $620 \mu \mathrm{g} / \mathrm{mL}$ for $<15 \mathrm{~min}$ in both cases, a concentration shown to affect canine corneal epithelial cell morphology and growth in vitro when cells are exposed to this level for $\geq 24 \mathrm{~h}$ (24).

Further interpretation of tear film PK of $1 \%$ prednisolone acetate highlights additional findings of relevance to clinical practice. First, tear prednisolone concentrations at $t=0 \mathrm{~min}$ (i.e., immediately upon mixing with the tear film) showed an approximately three-fold dilution of the applied drug (average $3.08 \mathrm{mg} / \mathrm{mL}$ ); this finding is consistent with data from one of our recent studies where we used fluorophotometry and data modeling to estimate a canine tear volume of 65.3 $\mu \mathrm{L}$ (25). Second, when comparing a single drop of $1 \%$ 
prednisolone acetate and oral administration of prednisone $(0.5-4.0 \mathrm{mg} / \mathrm{kg})(18)$, tear prednisolone concentrations (1-3,786 vs. $0.005-0.191 \mu \mathrm{g} / \mathrm{mL}$ ) and overall drug exposure $\left(\mathrm{AUC}_{\text {last }}\right.$, $10,434-40,399$ vs. $0.88-50.2 \mathrm{~min}^{*} \mu \mathrm{g} / \mathrm{mL}$ ) were much higher with the topical route. Therefore, an eye drop is preferred for treating inflammatory conditions of the avascular cornea. In contrast, the efficacy of both administration routes is likely comparable for diseases of the conjunctiva, based on drug AUCs in conjunctival samples of rabbits (26), although tissue concentrations were not evaluated in the present study. Third, the precorneal retention time of prednisolone ophthalmic suspension was relatively short in the present study, as the initial drug concentration drops by $\sim 45 \%$ within $1 \mathrm{~min}$ and $\sim 95 \%$ within $15 \mathrm{~min}$ of topical administration. This short retention time of an ophthalmic suspension is similar to reports of dogs receiving ophthalmic solutions such $1 \%$ fusidic acid (10), $0.3 \%$ ciprofloxacin (11), and $1 \%$ fluorescein (8).

Given the relatively short precorneal retention time of prednisolone suspension, other strategies could be considered to optimize the therapeutic efficacy of topical corticosteroids: (i) Increase the concentration of the formulation-a $1 \%$ preparation of prednisolone acetate produced higher drug concentrations in the eye (cornea, conjunctiva, aqueous humor) compared to 0.125 and $0.5 \%$ preparations $(6,15)$; however, $1 \%$ is the highest concentration that is commercially available, and further increases in concentration did not augment the therapeutic response in one study of inflammatory keratitis (27); (ii) Increase the viscosity of the formulation-drug concentrations in ocular tissues were higher when prednisolone was coupled with highly viscous polymers such as carboxypolymethylene (28) or carbomer $0.5 \%$ (6); (iii) Increase the frequency of administration-reduction in inflammatory cells invading the cornea was significantly better when prednisolone acetate was applied at $1 \mathrm{~h}$ compared to $4 \mathrm{~h}$ intervals, and was further improved when the drug was applied at $15 \mathrm{~min}$ intervals (29); (iv) Consider an alternate corticosteroid-for instance, $0.05 \%$ difluprednate administered at a lower frequency than $1 \%$ prednisolone acetate is at least as effective in controlling inflammation associated with paracentesis-induced uveitis in dogs (30) or endogenous uveitis in humans (31).

Clinicians need to balance the therapeutic benefits of corticotherapy (and aforementioned strategies to optimize response) with the potential local and systemic adverse effects associated with topical corticosteroid use $(1,2)$. In fact, cautious use of corticosteroids is always warranted, even when using topical formulations $(1,2)$. In the present study, $1 \%$ prednisolone acetate applied to both eyes four times daily for 3 days resulted in detectable drug levels in the blood. No significant differences were noted in plasma concentrations of dogs receiving 1 vs. 2 drops at each session, reinforcing the fact that the majority of the second drop is not systemically absorbed but is instead wasted by spillage over the periocular skin (8) or absorbed into the eye. Overall, an average of 2.0 and $1.2 \%$ of the applied dose ( 1 and 2 drops in both eyes per session, respectively) reached the systemic circulation-a fraction that is similar to findings in primates (1-7\%) (32). It is important to note, however, that these figures represent the minimum (and not total) dose absorbed since they do not account for the drug in the blood cell fraction or drug that diffused to peripheral tissues and other body fluids (e.g., liver, kidneys, bile, urine) $(32,33)$. Despite this underestimation, the fraction of the dose that is systemically absorbed in dogs is much lower than the typical value reported in several reviews on ocular pharmacology $(50-100 \%)(16,34-36)$. This discrepancy can be explained, in part, by a strong focus on the rabbit as the animal selected for basic research in ocular pharmacology; for instance, Sigurdsson et al. showed a $60 \%$ systemic absorption of topically applied dexamethasone, a fraction that was comparable to intravenous and intranasal administrations of the same dose in the same rabbits (37). However, the rabbit's eye is poorly representative of humans or companion animals given important differences in anatomy, physiology (e.g., very low blink rate) (38) and tear film dynamics $(8,25)$.

Plasma prednisolone levels detected in our dogs, albeit relatively small and potentially $50-100$-fold lower than other routes of administration (oral, peribulbar or subconjunctival injection) (39-41), are not completely without risk. Topical corticotherapy has been associated with systemic adverse effects in dogs of diverse size and body weight, namely suppression of the hypothalamic-hypophyseal-adrenal axis (up to the development of iatrogenic Cushing's) and hepatic glycogen accumulation (42-45), with similar concerns being reported in human patients $(46,47)$. Taken together, though topical prednisolone acetate is an excellent drug for inflammatory and immune-mediated diseases of the anterior segment of the eye, caution must be exercised to prevent unwanted and potentially serious adverse effects, regardless of a patient's size. Once inflammation is controlled, frequency of administration should be gradually reduced to find the lowest effective dose and minimize potential toxicity.

The main limitation of the study is the use of dogs from a single breed, all being relatively young and healthy. Tear film PK may differ slightly in smaller or larger canine breedspresumably due to differences in volume of the tear compartment and conjunctival cul-de-sac $(8,25,48)$ - or in older animals, in whom the ocular physiology and tear film dynamics may be altered (49-51). Similarly, patients with ocular diseases may have a different PK profile or systemic absorption following topical corticotherapy, either related to ocular irritation (e.g., reflex tearing) and/or disruption of ocular barriers (e.g., denuded corneal epithelium or breakdown of the blood-tear barrier) (33, 52). In fact, increased systemic absorption is well-documented for drugs administered topically on the inflamed skin $(53,54)$. Ultimately, the aforementioned factors could be addressed by modeling tears and plasma prednisolone concentrations obtained from a large group of dogs, representing a population of diverse characteristics such as sex, age, and health status (55). Two other limitations may be related to the study's methodology. First, blood sampling was performed at a single timepoint after each topical administration (10-15 min), hence the maximal plasma concentration could have been missed; however, a study on topical dexamethasone in humans undergoing vitrectomy surgery showed a comparable range of plasma concentrations whether blood was collected 3 to $101 \mathrm{~min}$ following eye drop administration (41). Second, the exact amount of prednisolone 
delivered to the eye may have differed from 1 day to another, despite an identical volume administered, as the distribution of drug particles in the ophthalmic suspension is heterogenous (56); however, this drawback was limited by transferring prednisolone suspension into Eppendorf vials that were vigorously shaken for 1 min with the same vortex mixer.

In conclusion, tear film prednisolone concentrations were high $(\sim 3.1 \mathrm{mg} / \mathrm{mL})$ immediately following topical administration of $1 \%$ prednisolone acetate ophthalmic suspension, although drug levels decreased rapidly by $\sim 45 \%$ at $1 \mathrm{~min}$ and $\sim 95 \%$ at $15 \mathrm{~min}$. Instillation of 2 drops vs. 1 drop provided a higher drug exposure to the ocular surface over the 12-h sampling period, although the clinical benefit or toxicity related to the second drop are likely negligible given the relatively low concentrations in tears beyond $\mathrm{t}=0 \mathrm{~min}$. Prednisolone acetate reached the systemic circulation at $\leq 2 \%$ of the dose applied to the ocular surface, with no differences in plasma levels between 1 and 2 drops applied 4 times daily for 3 days. Judicious use of topical corticotherapy is warranted in a clinical setting to optimize efficacy while minimizing local or systemic toxicity.

\section{REFERENCES}

1. McGhee CNJ, Dean S, Danesh-Meyer H. Locally administered ocular corticosteroids. Drug Safety. (2002) 25:33-55. doi: 10.2165/00002018-200225010-00004

2. Holmberg BJ, Maggs DJ. The use of corticosteroids to treat ocular inflammation. Vet Clin North Am Small Anim Pract. (2004) 34:693-705. doi: 10.1016/j.cvsm.2003.12.007

3. Leibowitz HM, Kupferman A. Anti-inflammatory effectiveness in the cornea of topically administered prednisolone. Invest Ophthalmol. (1974) 13:757-63

4. Awan MA, Agarwal PK, Watson DG, McGhee CNJ, Dutton GN. Penetration of topical and subconjunctival corticosteroids into human aqueous humour and its therapeutic significance. British J Ophthalmol. (2009) 93:708. doi: $10.1136 /$ bjo.2008.154906

5. Burch PG, Migeon CJ. Systemic absorption of topical steroids. Arch Ophthalmol. (1968) 79:174-6. doi: 10.1001/archopht.1968.03850040176013

6. Johansen S, Rask-Pedersen E, Prause JU. A bioavailability comparison in rabbits after a single topical ocular application of prednisolone acetate formulated as a high-viscosity gel and as an aqueous suspension. Acta Ophthalmol Scand. (1996) 74:253-8. doi: 10.1111/j.1600-0420.1996.tb00087.x

7. Vézina M. Comparative ocular anatomy in commonly used laboratory animals. In Weir AB, Collins M, editors. Assessing Ocular Toxicology in Laboratory Animals. (2013). (Totowa, NJ: Humana Press), 1-21

8. Sebbag L, Kirner NS, Allbaugh RA, Reis A, Mochel JP. Kinetics of fluorescein in tear film after eye drop instillation in beagle dogs: does size really matter? Front Vet Sci. (2019) 6:457. doi: 10.3389/fvets.2019.00457

9. Sebbag L, Mochel JP. An eye on the dog as the scientist's best friend for translational research in ophthalmology: focus on the ocular surface. Med Res Rev. (2020) 40:2566-604. doi: 10.1002/med.21716

10. van Bijsterveld OP, Andriesse H, Nielsen BH. Fusidic acid in tear fluid: pharmacokinetic study with fusidic acid viscous eye drops. Eur J Drug Metab Pharmacokinet. (1987) 12:215-8. doi: 10.1007/BF03189900

11. Hendrix DV, Cox SK. Pharmacokinetics of topically applied ciprofloxacin in tears of mesocephalic and brachycephalic dogs. Vet Ophthalmol. (2008) 11:7-10. doi: 10.1111/j.1463-5224.2007.00591.x

12. Sigmund AB, Ward DA, Cox SK, Hendrix DVH. Tear film concentrations of topically applied $0.5 \%$ oxytetracycline ointment in normal canine eyes. Vet Ophthalmol. (2020) 23:707-13. doi: 10.1111/vop.12783

13. Deng F, Ranta VP, Kidron H, Urtti A. General pharmacokinetic model for topically administered ocular drug dosage forms. Pharm Res. (2016) 33:2680-90. doi: 10.1007/s11095-016-1993-2

\section{DATA AVAILABILITY STATEMENT}

The raw data supporting the conclusions of this article will be made available by the authors, without undue reservation.

\section{ETHICS STATEMENT}

The animal study was reviewed and approved by the Institutional Animal Care and Use Committee at Iowa State University.

\section{AUTHOR CONTRIBUTIONS}

LS conceptualized and designed the study in consultation with JM. LS and NK performed the experiments. LS, LW, and JM analyzed the data. All authors wrote the manuscript.

\section{ACKNOWLEDGMENTS}

The authors are thankful to Kimberly Phillips for providing technical support.
14. Sasaki H, Yamamura K, Mukai T, Nishida K, Nakamura J, Nakashima M, et al. Enhancement of ocular drug penetration. Crit Rev Ther Drug Carrier Syst. (1999) 16:85-146.

15. Kupferman A, Leibowitz HM. Topically applied steroids in corneal disease. IV The role of drug concentration in stromal absorption of prednisolone acetate. Arch Ophthalmol. (1974) 91:377-80. doi: 10.1001/archopht.1974.03900060389009

16. Shell JW. Pharmacokinetics of topically applied ophthalmic drugs. Surv Ophthalmol. (1982) 26:207-18.

17. Sasaki H, Yamamura K, Nishida K, Nakamura J, Ichikawa M. Delivery of drugs to the eye by topical application. Progress Retinal Eye Res. (1996) 15:583-620. doi: 10.1016/1350-9462(96)00014-6

18. Sebbag L, Yan Y, Smith JS, Allbaugh RA, Wulf LW, Mochel JP. Tear fluid pharmacokinetics following oral prednisone administration in dogs with and without conjunctivitis. J Ocul Pharmacol Ther. (2019) 35:341-9. doi: 10.1089/jop.2019.0020

19. Sebbag L, Showman L, McDowell EM, Perera A, Mochel JP. Impact of flow rate, collection devices, and extraction methods on tear concentrations following oral administration of doxycycline in dogs and cats. J Ocul Pharmacol Ther. (2018) 34:452-9. doi: 10.1089/jop.2018. 0008

20. Spiess BM, Nyikos S, Stummer E, Sahin A, Naegeli H. Systemic dexamethasone concentration in horses after continued topical treatment with an ophthalmic preparation of dexamethasone. Am J Vet Res. (1999) 60:571-6.

21. Sebbag L, Harrington DM, Mochel JP. Tear fluid collection in dogs and cats using ophthalmic sponges. Vet Ophthalmol. (2018) 21:249-54. doi: $10.1111 /$ vop. 12502

22. Wamberg S, Sandgaard NC, Bie P. Simultaneous determination of total body water and plasma volume in conscious dogs by the indicator dilution principle. J Nutr. (2002) 132(6 Suppl 2):1711S-3S. doi: 10.1093/jn/132.6.1711S

23. Yan H, Wang Y, Shen S, Wu Z, Wan P. Corticosteroids effects on LPS-induced rat inflammatory keratocyte cell model. PLoS ONE. (2017) 12:e0176639. doi: 10.1371/journal.pone.0176639

24. Hendrix DV, Ward DA, Barnhill MA. Effects of anti-inflammatory drugs and preservatives on morphologic characteristics and migration of canine corneal epithelial cells in tissue culture. Vet Ophthalmol. (2002) 5:127-35. doi: 10.1046/j.1463-5224.2002.00218.x

25. Sebbag L, Allbaugh RA, Wehrman RF, Uhl LK, Ben-Shlomo G, Chen $\mathrm{T}$, et al. Fluorophotometric assessment of tear volume and turnover rate 
in healthy dogs and cats. J Ocul Pharmacol Ther. (2019) 35:497-502. doi: 10.1089/jop.2019.0038

26. Araki-Sasaki K, Katsuta O, Mano H, Nagano T, Nakamura M. The effects of oral and topical corticosteroid in rabbit corneas. BMC Ophthalmol. (2016) 16:160. doi: 10.1186/s12886-016-0339-5

27. Leibowitz HM, Kupferman A. Kinetics of topically administered prednisolone acetate. Optimal concentration for treatment of inflammatory keratitis. Arch Ophthalmol. (1976) 94:1387-9. doi: 10.1001/archopht.1976.03910040255019

28. Kupferman A, Ryan WJ, Leibowitz HM. Prolongation of antiinflammatory effect of prednisolone acetate. Influence of formulation in high-viscosity gel. Arch Ophthalmol. (1981) 99:2028-9. doi: 10.1001/archopht.1981.03930020904017

29. Leibowitz HM, Kupferman A. Optimal frequency of topical prednisolone administration. Arch Ophthalmol. (1979) 97:2154-6. doi: 10.1001/archopht.1979.01020020472014

30. Allbaugh R, Wehrman R, Sebbag L. Comparison of topically administered $0.05 \%$ difluprednate and $1 \%$ prednisolone acetate for inhibition of aqueocentesis-induced breakdown of the blood-aqueous barrier in healthy dogs. Am J Vet Res. (2020) 81:260-6. doi: 10.2460/ajvr.81.3.260

31. Sheppard JD, Toyos MM, Kempen JH, Kaur P, Foster CS. Difluprednate $0.05 \%$ vs. prednisolone acetate $1 \%$ for endogenous anterior uveitis: a phase III, multicenter, randomized study. Investig Ophthalmol Vis Sci. (2014) 55:29933002. doi: 10.1167/iovs.13-12660

32. Ohman L, Edqvist LE, Johansson ED. Absorption of topically applied hydrocortisone from the eye of the rhesus monkey. Acta Ophthalmol. (1982) 60:106-12. doi: 10.1111/j.1755-3768.1982.tb05786.x

33. Janes RG, Stiles JF. The penetration of cortisol into normal and pathologic rabbit eyes. Am J Ophthalmol. (1963) 56:84-90. doi: 10.1016/0002-9394(63)91306-0

34. Urtti A, Salminen L. Minimizing systemic absorption of topically administered ophthalmic drugs. Surv Ophthalmol. (1993) 37:435-56. doi: 10.1016/0039-6257(93)90141-s

35. Järvinen $\mathrm{K}$, Järvinen $\mathrm{T}$, Urtti A. Ocular absorption following topical delivery. Adv Drug Delivery Rev. (1995) 16:3-19. doi: 10.1016/0169-409X(95)00010-5

36. Farkouh A, Frigo P, Czejka M. Systemic side effects of eye drops: a pharmacokinetic perspective. Clin Ophthalmol. (2016) 10:2433-41. doi: 10.2147/OPTH.S118409

37. Sigurdsson HH, Konráethsdóttir F, Loftsson T, Stefánsson E. Topical and systemic absorption in delivery of dexamethasone to the anterior and posterior segments of the eye. Acta Ophthalmol Scand. (2007) 85:598-602. doi: $10.1111 / j \cdot 1600-0420.2007 .00885 . x$

38. Maurice D. The effect of the low blink rate in rabbits on topical drug penetration. J Ocul Pharmacol Ther. (1995) 11:297-304. doi: 10.1089/jop.1995.11.297

39. Weijtens O, van der Sluijs FA, Schoemaker RC, Lentjes EG, Cohen AF, Romijn FP, et al. Peribulbar corticosteroid injection: vitreal and serum concentrations after dexamethasone disodium phosphate injection. Am J Ophthalmol. (1997) 123:358-63. doi: 10.1016/s0002-9394(14)70131-x

40. Weijtens O, Feron EJ, Schoemaker RC, Cohen AF, Lentjes EG, Romijn FP, et al. High concentration of dexamethasone in aqueous and vitreous after subconjunctival injection. Am J Ophthalmol. (1999) 128:192-7. doi: 10.1016/s0002-9394(99)00129-4

41. Weijtens O, Schoemaker RC, Romijn FP, Cohen AF, Lentjes EG, van Meurs JC. Intraocular penetration and systemic absorption after topical application of dexamethasone disodium phosphate. Ophthalmology. (2002) 109:1887-91. doi: 10.1016/s0161-6420(02)01176-4

42. Roberts SM, Lavach JD, Macy DW, Severin GA. Effect of ophthalmic prednisolone acetate on the canine adrenal gland and hepatic function. Am $J$ Vet Res. (1984) 45:1711-4.
43. Zenoble RD, Kemppainen RJ. Adrenocortical suppression by topically applied corticosteroids in healthy dogs. J Am Vet Med Assoc. (1987) 191: $685-8$.

44. Eichenbaum J, Macy D, Severin G, Paulsen M. Effect in large dogs of ophthalmic prednisolone acetate on adrenal gland and hepatic function. J Am Animal Hospital Association. (1988) 24:705-9.

45. Glaze MB, Crawford MA, Nachreiner RF, Casey HW, Nafe LA, Kearney MT. Ophthalmic corticosteroid therapy: systemic effects in the dog. J Am Vet Med Assoc. (1988) 192:73-5.

46. Chiang MYM, Sarkar M, Koppens JM, Milles J, Shah P. Exogenous Cushing's syndrome and topical ocular steroids. Eye. (2006) 20:725-7. doi: 10.1038/sj.eye.6701956

47. Fukuhara D, Takiura T, Keino H, Okada AA, Yan K. Iatrogenic cushing's syndrome due to topical ocular glucocorticoid treatment. Pediatrics. (2017) 139:e20161233. doi: 10.1542/peds.2016-1233

48. Oriá AP, Rebouças MF, Martins Filho E, Dórea Neto FA, Raposo AC, Sebbag L. Photography-based method for assessing fluorescein clearance test in dogs. BMC Vet Res. (2018) 14:269. doi: 10.1186/s12917-0181593-y

49. Sun WS, Baker RS, Chuke JC, Rouholiman BR, Hasan SA, Gaza W, et al. Age-related changes in human blinks. Passive and active changes in eyelid kinematics. Invest Ophthalmol Vis Sci. (1997) 38:92-9.

50. Van Haeringen NJ. Aging and the lacrimal system. Br J Ophthalmol. (1997) 81:824-6. doi: 10.1136/bjo.81.10.824

51. Harigaya Y, Jiang X, Zhang H, Chandaroy P, Stier EM, Pan Y. Bioequivalence study methods with pharmacokinetic endpoints for topical ophthalmic corticosteroid suspensions and effects of subject demographics. Pharm Res. (2018) 36:13. doi: 10.1007/s11095-018-2537-8

52. Sebbag L, Allbaugh RA, Weaver A, Seo YJ, Mochel JP. Histamine-induced conjunctivitis and breakdown of blood-tear barrier in dogs: a model for ocular pharmacology and therapeutics. Front Pharmacol. (2019) 10:752. doi: 10.3389/fphar.2019.00752

53. Aalto-Korte K, Turpeinen M. Quantifying systemic absorption of topical hydrocortisone in erythroderma. Br J Dermatol. (1995) 133:403-8. doi: 10.1111/j.1365-2133.1995.tb02668.x

54. Hazama Y, Maekawa T, Miki R, Oshima S, Egawa Y, Morimoto K, et al. Effect of physiological changes in the skin on systemic absorption of tacrolimus following topical application in rats. Biol Pharm Bull. (2016) 39:343-52. doi: 10.1248/bpb.b15-00727

55. Pelligand L, Soubret A, King JN, Elliott J, Mochel JP. Modeling of large pharmacokinetic data using nonlinear mixed-effects: a paradigm shift in veterinary pharmacology. A case study with robenacoxib in cats. CPT Pharmacometrics Syst Pharmacol. (2016) 5:625-35. doi: 10.1002/psp 4.12141

56. Roberts CW, Nelson PL. Comparative analysis of prednisolone acetate suspensions. J Ocul Pharmacol Ther. (2007) 23:182-7. doi: 10.1089/jop.2006.0070

Conflict of Interest: The authors declare that the research was conducted in the absence of any commercial or financial relationships that could be construed as a potential conflict of interest.

Copyright $(2020$ Sebbag, Kirner, Wulf and Mochel. This is an open-access article distributed under the terms of the Creative Commons Attribution License (CC BY). The use, distribution or reproduction in other forums is permitted, provided the original author(s) and the copyright owner(s) are credited and that the original publication in this journal is cited, in accordance with accepted academic practice. No use, distribution or reproduction is permitted which does not comply with these terms. 